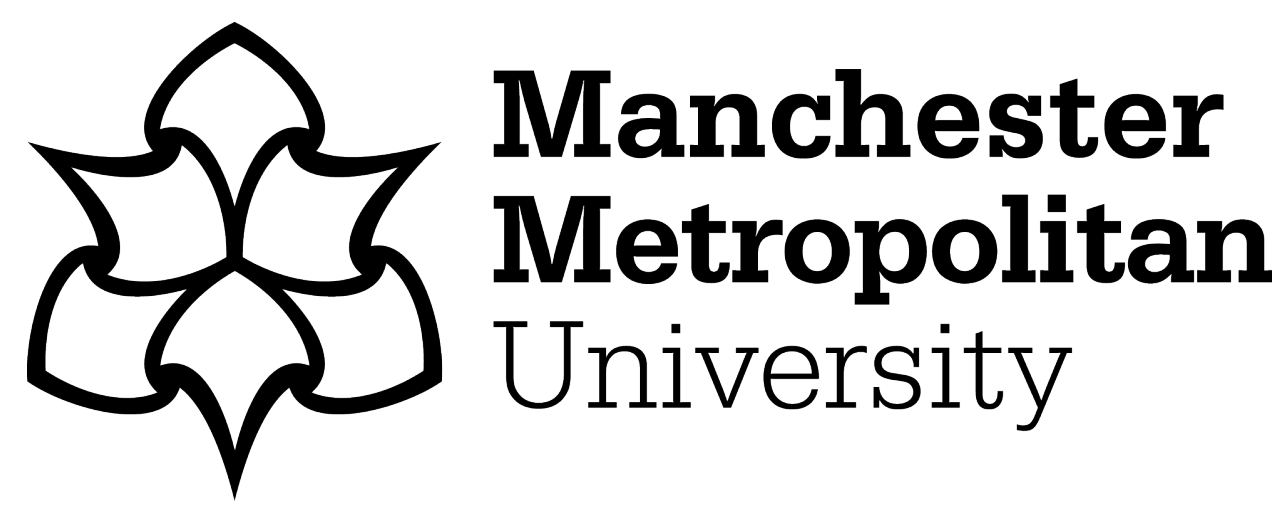

Giovanis, Eleftherios (2014) Study of discrete choice models and fuzzy rule based systems in the prediction of economic crisis periods in USA. Fuzzy Economic Review: review of the International Association for Fuzzy-set Management and Economy, XIX (1). pp. 3-18. ISSN 1136-0593

Downloaded from: https://e-space.mmu.ac.uk/620956/

Version: Accepted Version

Publisher: SIGEF International Association for Fuzzy-Set Management and Economy

Please cite the published version 


\title{
STUDY OF DISCRETE CHOICE MODELS AND FUZZY RULE BASED SYSTEMS IN THE PREDICTION OF ECONOMIC CRISIS PERIODS IN USA
}

\author{
Eleftherios Giovanis ${ }^{a}$
}

This paper studies the economic recessions and the financial crisis in US economy, as these crisis periods affect not only USA but the rest of the world. The wrong government policies and the regulations in bond market among others lead to the longest and deepest financial crisis since the Great depression of 1929. In this paper we examine three models in order to predict the economic recession or expansion periods in USA. The first one is the Logit model, the second is the Probit model and the last one is a fuzzy rule based system binary regression with sigmoid membership function. We examine the in-sample period 19132005 and we test the models in the outof sample period 2006-2009. The estimation results indicate that the fuzzy regression outperforms the Logit and Probit models, especially in the out-of sample period. This indicates that fuzzy regressions provide a better and more reliable signal on whether or not a financial crisis will take place. Furthermore, based on the estimated values for the period 1913-2009 we estimate the forecasts to investigate if the economic recession will be continued or not during 2010. The conclusion is that Logit model presents a signal that the economic recession will be continued during the whole period 2010, while based on Probit and fuzzy regressions the economic recovery might begin in the second half of 2010.

Keywords: financial crisis, discrete choice models, fuzzy rules, fuzzy regression, sigmoid membership function

JEL Classification: C53, E17

\section{INTRODUCTION}

The economic facts and the financial crisis in the last three years lead to doubts among the economic society and governments of which methodology must be followed and what regulations should be set up. The subprime mortgage crisis which took place in USA and became apparent in 2007 led to great weakness in the financial system and the financial industry regulation. Furthermore, even if economists and policy makers nowadays have in their disposable management portfolio, improved estimation methods, access in long databases and mainly the use of very fast computers and advanced algorithms and computational

a Bologna University, Via Strada Maggiore 45, 40125, Bologna, Italy Royal Holloway University of London, TW20 0EX, Egham, England. 
methods, where they are able to get the estimating results in a few minutes they didn't manage to forecast the crisis or even if they predicted the crisis they were unable to take the appropriate measures in order to eliminate it or to confront the situation. This indicates that models are not always enough to take decisions as equivalently significant is the correct and efficient government policies and the optimal set up of the financial regulations. In this paper we examine the methodology and the models which can be applied in order to predict very successfully the crisis periods, rather than to comment or propose the formulation of regulations in financial and market industry.

Various approaches have been developed and applied in financial, banking and currency crisis. One of these approaches is the application of Logit and Probit models (Eichengreen and Rose,1998; Demirguc-Kunt and Detragrache ,1998; Frankel and Rose, 1996; Glick and Rose, 1998; Glick and Moreno, 1999). In this approach the dependent variable is a dummy variable taking two values, the value 1 for crisis periods and the value 0 for no crisis periods. More specifically Demirguc-Kunt and Detragrache (1998) found that low GDP growth high inflation and high interest rates might lead to economic downturns, which are the most significant variables among other macroeconomic factors. Eichengreen and Rose (1998), found that the Northern interest rates are strongly connected with the onset of banking crises in the developing countries. The methodology of Probit and Logit models is that allows for statistical testing, identifying the sign, the magnitude and the marginal distributions of the explanatory variables to the onset of crisis. On the other hand this approach confronts the problem of misspecification errors and serial correlation.

Another approach which has been used in the crisis prediction is the noise-toratio model (Kaminsky and Reinhart, 1996; Kaminsky et al., 1998). This approach is used in order to identify variables as strong potential indicators of crisis. Kaminsky and Reinhart (1996) examined monthly data for 23 crises and they found that the economic downturn precedes the banking crisis, where specifically the output tends to peak roughly eight months before a crisis take place. Kaminsky et al., (1998) found that exports, the deviations of the real exchange rates from the trend, the output and equity prices are strong potential indicators providing a warning signal that a crisis will take place. Also they found that when an indicator exceeds a specific threshold, then a banking crisis might take place in the following 24 months. The advantage of this approach is that we can directly rank the possible candidate variables as potential crisis periods, but it doesn't allow for statistical testing and it's not possible to examine the magnitude of each explanatory variable to crisis phenomena.

An alternative approach is Markov Switching Regime Autoregressive models (MS-AR) which has been developed by Hamilton (1989). Mariano et al. (2001) followed this approach and specifically estimated a Markov switching model with time varying transition probabilities. This model allows for sharp movements between the regimes, so it's able to describe sudden shifts and changes through regimes. Furthermore, the model avoids the misclassification 
errors and serial correlation as in Probit and Logit models. The problem is that MS-AR model is based on the econometrical estimation procedure of crisp numbers rather fuzzy number as we apply in fuzzy regressions.

Since 1990 new approaches have been introduced in economics and finance, which are neural networks, fuzzy logic and genetic algorithms. The most researches and studies that have been made in the finance scientific field, have found superior and significant results in relation with the traditional econometrical and statistical approaches. Nachev and Stoyanov, (2007) propose that the prediction of corporate bankruptcy can be viewed as a pattern recognition problem and they estimate an ARTMAP neural networks model for financial diagnosis. Other researches compare the neural networks with traditional statistical approaches and their results show that neural networks outperform significant the other statistical methods (Zhang et al., 1999; Coats and Fant, 1993; Fernandez and Olmeda, 1995). Chen and Du (2009) compare artificial neural networks (ANN) and data mining techniques developing a financial distress model and they found that ANN presents better prediction accuracies than data mining techniques, suggesting that artificial intelligence can be a more suitably methodology than traditional statistical approaches.

We should mention that artificial intelligence $(\mathrm{Al})$ is not always panacea. If the traditional econometrical and statistical approaches lead to reliable and significant results, then there is not necessary to obtain artificial intelligence models. Also even if we should take artificial intelligence models we must be careful in their formulation as wrong set up lead to great biases and even in worse results than with traditional econometrical approaches. In this paper we compare Logit and fuzzy regression and we find results supporting significantly fuzzy regressions.

\section{METHODOLOGY}

\subsection{Binary Logit and Probit Regressions}

In this section we provide a brief description of the binary Logit and Probit models estimation.. The logistic distribution is defined as

$$
\operatorname{Prob}(Y=1 \mid x)=\frac{e^{x^{\prime} \beta}}{1+e^{x^{\prime} \beta}}=\Phi\left(x^{\prime} \beta\right)
$$

The marginal partial effects of explanatory variables are given by:

$$
\frac{\partial E[y \mid x)}{\partial x}=\Phi\left(x^{\prime} \beta\right)\left[1-\Phi\left(x^{\prime} \beta\right)\right] \beta
$$

The logistic regression analyzes the binomial distributed data and it's

$$
Y_{i} \sim B\left(n_{i}, P_{i}\right), \quad i=1,2, \ldots \ldots, n
$$


where $n_{i}$ denotes the number of Bernoulli trials and are known, while $p_{i}$ denotes the probabilities of success, which are unknown. The model proposes for each $\mathrm{i}$ a set of explanatory variables and the model can take the following form.

$$
P_{i}=E\left(\frac{Y_{i}}{n_{i}} \mid x_{i}\right)
$$

Next the unknown probabilities are modeled as linear function of variables $x_{i}$.

$$
y_{i}=\ln \left(\frac{p_{i}}{1-p_{i}}\right)=\beta_{0}+\beta_{1} x_{1, i}+\beta_{2} x_{2, i}+\ldots . .+\beta_{k} x_{k, i}
$$

An alternative formulation of the model is:

$$
p_{i}=\frac{1}{1+e^{-\left(\beta_{0}+\beta_{1} x_{1, i}+\beta_{2} x_{2, i}+\ldots . .+\beta_{k} x_{k, i}\right)}}
$$

Logit model can be written a general form regression as:

$$
y=\alpha+\sum_{i=1}^{n} \beta_{i} x_{i}+\varepsilon
$$

where variable $y$ is a binary dummy variable taking value 1 if the economy is on crisis or economic recession period and value zero otherwise (no crisis period), $x_{i}$ indicates the explanatory variables, $\alpha$ is the constant, $\beta_{i}$ are the regression estimators.

Next we present the Probit regression. More specifically it's:

$$
\Phi^{-1}\left(p_{i}\right)=Z=\alpha+\sum_{i=1}^{n} \beta_{i} x_{i}+\varepsilon
$$

where $\Phi^{-1}\left(p_{i}\right)$ is the inverse cumulative distribution function (CDF) of the standard normal, $a, \beta_{i}$ and $x_{i}$ are defined as in (7). Also it can be written as:

$$
\operatorname{Pr}(\mathrm{y}=1 \mid \mathrm{x})=\Phi\left(\mathrm{x}_{\mathrm{i}} \beta_{\mathrm{i}}\right)
$$

The inverse cumulative distribution function (CDF) is

$$
\mathrm{p}=\Phi(Z)=\int_{-\infty}^{\mathrm{Z}} \frac{1}{\sqrt{2 \pi}} \exp \left(-\mathrm{u}^{2} / 2\right) \mathrm{du}
$$

The Log-Likelihood function for Probit is:

$$
\ln L=\sum w_{i} \ln \Phi\left(x_{i} \beta_{i}\right)+\sum w_{i} \ln \left(1-\Phi\left(x_{i} \beta_{i}\right)\right)
$$


The prediction or the classification percentage is done based on the estimated coefficients from the in-sample period each time using as the cut-off point the value of 0.5 . For the forecasting and the classification performance of the binary Logit and Probit models are:

If $y^{*}>0.5$, then the economy is on crisis or economic recession period

If $y^{*} \leq 0.5$, then the economy is on no crisis or economic recovery period.

Variable $\mathrm{y}^{*}$ denotes the predicted values.

\subsection{BINARY FuZZY REGRESSION}

In this section we provide the methodology of fuzzy regressions with sigmoid and triangular membership fuzzy functions. As we see in relation (7) the dependent variable contains crisp number. In order to formulate the fuzzy regression the dependent variable should obtain fuzzy number and is modified as (Papadopoulos and Sirpi, 1999):

$$
y\left(x_{i}\right)=A_{0}+A_{1} x_{1 t}+A_{2} x_{2 t}+\ldots \ldots .+A_{i} x_{i t}
$$

where $y\left(x_{i}\right)$ is the fuzzy dependent variables, $A_{n}$ is the fuzzy parameters for $n=1,2, \ldots . i$ and the vector $\left(x_{1 t}, x_{1 t}, \ldots ., x_{i t}\right)$ is the vector of the independent variables. We assume two fuzzy membership functions. The first one is the sigmoid and the second one the triangular membership function.

First we should identify and set the inference fuzzy rules IF-THEN. According to Aznarte et al. (2007) a fuzzy Rule Based System consists by the rule base, containing a selection of fuzzy rules, the fuzzy rules database, which contains the membership functions and the reasoning mechanism, which contains the inference procedure to derive a reasonable output. So this system is based on IF-THEN rules and fuzzy reasoning. A Takagi-Sugeno-Kang (TSK) fuzzy rule based system has the following shape:

$$
\text { If } x_{1} \text { is } A_{1} \text { and } x_{2} \text { is } A_{2} \text { and ..... } x_{p} \text { is } A_{p}
$$

Then

$$
y_{t}=b_{0}+b_{1} x_{1}+b_{2} x_{2}+\ldots+b_{p} x_{p}
$$

The second step is to set up the database which defines the membership function of the fuzzy sets used in fuzzy rules. The firing strength of ith rules is defined as:

$$
w_{i}(y)=\prod_{j=1}^{p} \phi_{A_{j}^{i}}\left(y_{j}\right)
$$


where $i$ express the number of the fuzzy rules, $j$ the number of independent variables and $\mu_{A_{j}^{i}}$ indicates the shape of the membership function, which in the case we examine is the sigmoid and is defined as:

$$
\phi_{\mathrm{A}}(\mathrm{y})=\frac{1}{1+\exp (-\gamma(\mathrm{y}-\mathrm{c}))}
$$

Parameter $\mathrm{y}$ indicates the speed of the transition between the regimes or the states and it's the slope of the membership function, while the parameter $c$ denotes the threshold value giving the location of the membership function. As we present the Probit results, GDP growth, as it was expected, is the major factor and presents the most significant magnitude and strongest impact of whether or not an economic crisis will take place and whether the economic recession will be continued or economic recovery will begin. For this reason based on Probit model estimated results we define the fuzzy rules based on GDP growth. We define the following fuzzy rules:

If $\mathrm{GDP}_{\mathrm{t}-1}, \mathrm{GDP}_{\mathrm{t}-2}, \mathrm{GDP}_{\mathrm{t}-3}$ and $\mathrm{GDP}_{\mathrm{t}-4}$ are negative or positive and

lower than 1.0 percent then it's a crisis period

If $\mathrm{GDP}_{\mathrm{t}-1}, \mathrm{GDP}_{\mathrm{t}-2}, \mathrm{GDP}_{\mathrm{t}-3}$ and $\mathrm{GDP}_{\mathrm{t}-4}$ are positive but lower than 2.0

per cent and higher than 1.0 per cent then it's a pre-crisis or

growth-recession period

If $\mathrm{GDP}_{\mathrm{t}-1}, \mathrm{GDP}_{\mathrm{t}-2}, \mathrm{GDP}_{\mathrm{t}-3}$ and $\mathrm{GDP}_{\mathrm{t}-4}$ are positive and higher

than 2.0 per cent then it's a growth or recovery period

where the lag periods are referred in quarters. Because we have three rules and we need to formulate the dummy crisp variable $y$ into a fuzzy variable, relation (14) becomes:

$$
\begin{aligned}
\phi_{A}\left(y_{1}\right) & =\frac{1}{1+\exp \left(-\gamma_{1}\left(y-c_{1}\right)\right)} \\
\phi_{A}\left(y_{2}\right) & =\frac{1}{1+\exp \left(-\gamma_{2}\left(y-c_{2}\right)\right)} \\
\phi_{A}\left(y_{3}\right) & =\frac{1}{1+\exp \left(-\gamma_{3}\left(y-c_{3}\right)\right)}
\end{aligned}
$$

where relations (16.a)-(16.c) are referred respectively to the rules (15.a)-(15.c). In order to compute the values of parameters $c$ and $y$ we apply a grid search method nonlinear least squares method in relations (16.a)-(16.c) with Levenberg-Marquardt algorithm. More specifically we apply the grid search for parameters $c_{1}, C_{2}$ and $c_{3}$ in the intervals [ 0.71$]$, [ $\left[\begin{array}{ll}0.4 & 0.6\end{array}\right]$ and [ 00.3$]$ respectively and initial values the mean of variable $y$. For parameters $\gamma_{1}, Y_{2}$ and $\gamma_{3}$ the grid 
search takes place in a common interval which is [1 10] and initial value 1. In all grid search applications the increment is set up at 0.1 . If the first rule is satisfied than we obtain $\phi_{\mathrm{A}}\left(\mathrm{y}_{1}\right)$ as the dependent variable and the same process is followed for the other rules.

The last step is to apply the forecasts, which is common for both fuzzy regressions we examine. The predicted values are given by relation (17).

$$
y^{*}=x_{i} A_{i}
$$

where $y^{*}$ denotes the forecasted fuzzy values, $x_{i}$ is the matrix of the independent variables including constant and $A_{i}$ are the estimated parameters. In order to find the classification and forecasts we should convert the fuzzy values to crisp numbers. For this purpose we prefer to take the centroid defuzzification method, which is defined as:

$$
\text { Output }=\frac{\sum_{i=1}^{n} y\left(z_{i}\right) z_{i} J_{i}}{\sum_{i=1}^{n} y\left(z_{i}\right) J_{i}}
$$

where $\mathrm{z}_{\mathrm{i}}$ and $\mathrm{J}_{\mathrm{i}}$ are the centroid and area of the ith predicted values and $\mathrm{n}$ is the number of output membership functions. The correctly classification percentage is:

If $\mathrm{y}^{*}>$ Output, then economy is on crisis or economic recession period

If $\mathrm{y}^{*} \leq$ Output, then economy is on no crisis or economic recovery period

where $\mathrm{y}^{*}$ is defined as previously.

\section{DATA AND RESEARCH DESIGN}

We examine two in-sample and out-of sample periods. Specifically, first we estimate the period 1913-2005 and we examine the in-sample forecasting performance. Then we apply all the models to compare their predicting performance for the period 2006-2009. In the following step we estimate the period 1913-2009 and we investigate the forecasting performance for the insample period, which is 1913-2009 and then we present the forecasts for the year 2010. The data source is the Federal Reserve Bank of St. Louis and the National Bureau of Economic Research and based on their availability and because we would like to obtain a long sample, including the Great depression of 1929, are in quarter frequency and concern specific variables. We use 12 variables and these are presented in Table 1. 
Table 1. Variables used in estimated regressions

\begin{tabular}{ll}
\hline $\begin{array}{l}\text { industrial production } \\
\text { inflation rate }\end{array}$ & $\begin{array}{l}\text { unemployment rate } \\
\text { total investments at all } \\
\text { commercial banks } \\
\text { total borrowings of depository } \\
\text { institutions from federal reserve }\end{array}$ \\
$\begin{array}{l}\text { system } \\
\text { interest rates of 3-monthly treasury } \\
\text { bills }\end{array}$ & bank prime loan rate \\
us public debt & balance of accounts \\
total loans at all commercial banks & gdp growth \\
\hline
\end{tabular}

\section{EMPIRICAL RESULTS}

In this section the estimation results are shown. For the Logit and Probit regression we use the same variables, while for fuzzy regression we use different variables depending on the statistical significance of each variable.

\subsection{Binary Logit and Probit Regressions}

In Tables 2 and 5 we present the estimation results of binary Logit and Probit regressions. We observe that an increase in the total loans, the oil prices, the bank prime loan rate and the balance of accounts leads to an increase of the probability of crisis occurrence, while an increase on remaining variables leads to decrease. More specifically the strongest positive effects presents the bank prime loan rate as we observe in the column which presents the marginal effects of Logit and Probit regressions. So we conclude that the primary variable or factor leading to financial crisis is bank prime loan rate, where this factor probably led to the current financial crisis as the increase from 5.25 in 2005 to 8.25 in 2007 was relatively high. Also the bank prime loan rate is decreased at 3.25 through 2009 and will be continued at this value during 2010 and this probably be one of the factors among others, which might lead to the growth of the economy.

On the other hand if the industrial production, the interest rates, the total investments and GDP growth increased then the risk of financial crisis occurrence is decreased. We should mention that the marginal effect of GDP growth in Logit regression is wrong as increase in GDP lead to significant decreasing of the probability of a crisis occurrence as other studies have found as we mentioned previously, while the marginal effect of Logit model we examine is almost zero. This problem is eliminated with Probit regression so the last model is more appropriate. 
In Table 3 we present the correctly percentage or the forecasts of Logit regression for the in-sample period 1913-2005, while in the Table 3 the forecasts of the same model for the out-of sample period 2006-2009 are provided. We observe that the forecasting performance in the in-sample period is relatively significant, while in the out-of sample is too poor. The value NaN indicates that is Non Available, as the Logit model it's not able to forecast correctly the no crisis periods with a percentage of success $0.00 \%$. In Tables 6 and 7 we present the same results as those of tables 2 and 3, for Probit regression. We observe that in the in-sample period 1913-2005 Probit presents slightly superior results with Logit model. In the out-of sample period 2006-2009 Probit predicts 100.00 per cent correct the no crisis periods, but only 71.42 per cent the crisis periods, which is higher of the predicted percentage of Logit models, but still is low in relation with fuzzy predictions as we show in the next part. We should mention that we don't present the estimating results for the period 1913-2009 as the estimating coefficients are almost identical. But in order to find the forecasting values for 2010 we use the estimated coefficients of the period 1913-2009. The exactly same process is followed for the fuzzy regressions as in this case too the estimated coefficients are almost the same.

Table 2. Results of binary Logit regression for period 1913-2005

\begin{tabular}{|c|c|c|c|c|c|c|}
\hline Variable & $\begin{array}{l}\text { Estimated } \\
\text { Coefficients }\end{array}$ & $\begin{array}{l}\text { Standard } \\
\text { Errors }\end{array}$ & $\begin{array}{l}\text { Z- } \\
\text { statistics }\end{array}$ & $\begin{array}{l}\text { P- } \\
\text { Value }\end{array}$ & $\begin{array}{l}\text { Marginal } \\
\text { Effects }\end{array}$ & $\begin{array}{l}\text { Diagnostic } \\
\text { Tests }\end{array}$ \\
\hline Constant & 2.031 & 0.768 & 2.64 & 0.002 & & Pseudo $\mathrm{R}^{2}$ \\
\hline $\begin{array}{l}\text { Industrial } \\
\text { Production }\end{array}$ & -0.1388 & 0.045 & -3.07 & 0.000 & 0.870 & 0.3543 \\
\hline $\begin{array}{l}\text { 3-monthly } \\
\text { interest } \\
\text { rates }\end{array}$ & -1.6280 & 0.433 & -3.76 & 0.001 & 0.196 & $\operatorname{LR} x^{2}$ \\
\hline $\begin{array}{l}\text { Total } \\
\text { Loans }\end{array}$ & 0.0099 & 0.003 & 3.19 & 0.011 & 1.010 & \multirow{2}{*}{$\begin{array}{l}140.96 \\
{[0.000]} \\
\text { Log- } \\
\text { Likelihood }\end{array}$} \\
\hline $\begin{array}{l}\text { Total } \\
\text { Investments }\end{array}$ & -0.0253 & 0.009 & -2.55 & 0.465 & 0.974 & \\
\hline Oil Prices & 0.0358 & 0.049 & 0.73 & 0.000 & 1.036 & \multirow{2}{*}{$\begin{array}{l}-128.440 \\
\text { Akaike } \\
\text { criterion }\end{array}$} \\
\hline $\begin{array}{l}\text { Bank Prime } \\
\text { Loan Rate }\end{array}$ & 1.7739 & 0.374 & 4.74 & 0.156 & 5.894 & \\
\hline $\begin{array}{l}\text { Balance of } \\
\text { Accounts }\end{array}$ & 0.0105 & 0.007 & 1.42 & 0.000 & 1.010 & \multirow[t]{2}{*}{274.881} \\
\hline $\begin{array}{l}\text { GDP } \\
\text { Growth }\end{array}$ & -188.559 & 3.683 & -5.12 & 0.008 & $1.29 e-82$ & \\
\hline
\end{tabular}

* denotes statistically significant in 0.01 level, ${ }^{* *}$ denotes statistically significant in 0.10 level, p-value in bracket, p-value in bracket. 
Table 3. Prediction results of binary Logit regression for insample period 1913-2005

\begin{tabular}{lllll}
\hline Actual & \multicolumn{3}{l}{ Prediction } & \\
\hline & Crisis & No Crisis & $\begin{array}{l}\text { Correctly } \\
\text { rate }\end{array}$ & percentage \\
Crisis & 35 & 16 & 68.63 & \\
No Crisis & 55 & 242 & 81.48 & \\
Overall & & & 79.60 & \\
percentage & & & & \\
\hline
\end{tabular}

Table 4. Prediction results of binary Logit regression for out-of sample period 2006-2009

\begin{tabular}{llll}
\hline Actual & \multicolumn{3}{l}{ Prediction } \\
\hline & Crisis & No Crisis & $\begin{array}{l}\text { Correctly percentage } \\
\text { rate }\end{array}$ \\
& & & 62.50 \\
Crisis & 10 & 6 & $\mathrm{NaN}$ \\
No Crisis & 0 & 0 & 62.50 \\
Overall percentage & & & \\
\hline
\end{tabular}

Table 5. Results of binary Probit regression for period 1913-2005

\begin{tabular}{|c|c|c|c|c|c|c|}
\hline Variable & $\begin{array}{l}\text { Estimated } \\
\text { Coefficients }\end{array}$ & $\begin{array}{l}\text { Standard } \\
\text { Errors }\end{array}$ & $\begin{array}{l}\text { Z- } \\
\text { statistics }\end{array}$ & $\begin{array}{l}\text { P- } \\
\text { Value }\end{array}$ & $\begin{array}{l}\text { Marginal } \\
\text { Effects }\end{array}$ & $\begin{array}{l}\text { Diagnostic } \\
\text { Tests }\end{array}$ \\
\hline Constant & 1.1317 & 0.4244 & 2.67 & 0.008 & & \multirow{3}{*}{$\begin{array}{l}\text { Pseudo } R^{2} \\
0.3531 \\
L R x^{2}\end{array}$} \\
\hline \multirow{2}{*}{$\begin{array}{l}\text { Industrial Production } \\
\text { 3-monthly interest } \\
\text { rates }\end{array}$} & -0.0779 & 0.025 & -3.180 & 0.001 & -0.016 & \\
\hline & -0.8534 & 0.230 & -3.710 & 0.000 & -0.172 & \\
\hline Total Loans & 0.0052 & 0.002 & 3.140 & 0.002 & 0.001 & \multirow{2}{*}{$\begin{array}{l}140.47 \\
{[0.000]} \\
\text { Log- } \\
\text { Likelihood }\end{array}$} \\
\hline Total Investments & -0.0124 & 0.005 & -2.450 & 0.014 & -0.003 & \\
\hline \multirow{3}{*}{$\begin{array}{l}\text { Oil Prices } \\
\text { Bank Prime Loan } \\
\text { Rate } \\
\text { Balance of Accounts } \\
\text { GDP Growth }\end{array}$} & 0.0228 & 0.025 & 0.920 & 0.359 & 0.005 & \multirow{3}{*}{$\begin{array}{l}-128.685 \\
\text { Akaike } \\
\text { criterion } \\
275.370\end{array}$} \\
\hline & 0.9364 & 0.193 & 4.840 & 0.000 & 0.189 & \\
\hline & $\begin{array}{l}0.0062 \\
-104.9097\end{array}$ & $\begin{array}{l}0.004 \\
18.821\end{array}$ & $\begin{array}{l}1.490 \\
-5.570\end{array}$ & $\begin{array}{l}0.137 \\
0.000\end{array}$ & $\begin{array}{l}0.001 \\
-21.129\end{array}$ & \\
\hline
\end{tabular}


Table 6. Prediction results of binary Probit regression for insample period 1913-2005

\begin{tabular}{llll}
\hline Actual & \multicolumn{2}{l}{ Prediction } & \\
& Crisis & No Crisis & Correctly percentage \\
& & & rate \\
Crisis & 39 & 11 & 78.00 \\
No Crisis & 51 & 247 & 82.88 \\
Overall percentage & & & 82.18 \\
\hline
\end{tabular}

Table 7. Prediction results of binary Probit regression for out-of sample period 2006-2009

\begin{tabular}{llll}
\hline Actual & \multicolumn{3}{l}{ Prediction } \\
& Crisis & No Crisis & Correctly percentage \\
& & & rate \\
Crisis & 10 & 4 & 71.42 \\
No Crisis & 0 & 2 & 100.00 \\
Overall percentage & & & 75.00 \\
\hline
\end{tabular}

\subsection{BINARY FUZZY REGRESSIONS}

The values we found with the grid search method for parameters $c_{1}, c_{2}, c_{3}, Y_{1}, Y_{2}$ and $\gamma_{3}$ are reported in Table 8. We must notice that we get the same estimated parameters for both 1913-2005 and 1913-2009 periods. We observe that $\gamma_{1}, \gamma_{2}$ denoting crisis and pre crisis periods are high indicating that the transition between these regimes is sharp. This suggests that Markov Switching Regimes and Threshold autoregressive (TAR) models might be more appropriate than Smoothing Transition Autoregressive (STAR) models, where STAR models assume a smoothly rather a sharply transition between the regimes. Also the last estimated parameter $\mathrm{y}_{3}$ is low, which means that the transition to economic recovery is rather smoothly.

In Table 9 the fuzzy regression estimations with sigmoid membership function are reported. We observe that, Industrial production, interest rates, and GDP growth have negative sign so an increase of these variables leads to a decrease of the crisis occurrence probability. The remaining coefficients present positive sign, which mean that when, are increased then the probability of crisis onset is increased too. Furthermore we observe that GDP growth is statistically significant and presents the strongest effects in the crisis or no crisis occurrence, which is on contrary with the results we found previously with the Logit model. This was expected and shows the weakness of Logit regression. The GDP presents a very significant difference in effects than the other variables. 
On the other hand the bank prime loan rate followed by total borrowings and unemployment rate present the strongest effects on a crisis occurrence and then oil prices and public debt are followed, concerning their significance on the probability of crisis occurrence which is rather small. So the bank prime loan rate, total borrowings, unemployment rate and GDP growth could be the reasons of the current crisis. Low GDP growth, high bank prime loan rate high unemployment rate and high total borrowings have led to the current financial crisis, as also the high oil prices. Finally, in Tables 10 and 11 the forecasting and the correctly classification percentages for the in-sample and out-of sample periods respectively are reported. The defuzzification value was found equal with 0.45274 . So for values greater than 0.45274 there is crisis and for values lower than 0. 45274 there is no crisis. In both samples fuzzy regression outperforms the forecasts generated by Logit and Probit models, especially in the out-of sample period. More specifically in the out-sample period 2006-2009 fuzzy regression predicts correctly 100.00 per cent the crisis periods and the no crisis periods at 85.71 per cent with an overall correct classification percentage of 93.75 . per cent.

Table 8. Estimated parameters $\alpha$ and $c$

\begin{tabular}{llllll}
\hline$\alpha_{1}$ & $\alpha_{2}$ & $\alpha_{3}$ & $c_{1}$ & $c_{2}$ & $c_{3}$ \\
\hline 5.5 & 5.5 & 1.201 & 0.9 & 0.6 & 1.21 \\
\hline
\end{tabular}

Table 9. Estimation Results of binary fuzzy regression with sigmoid membership function for period 1913-2005

\begin{tabular}{|c|c|c|c|c|c|}
\hline Variable & $\begin{array}{l}\text { Estimated } \\
\text { Coefficients }\end{array}$ & $\begin{array}{l}\text { Standard } \\
\text { Errors }\end{array}$ & $\begin{array}{l}\text { Z- } \\
\text { statistics }\end{array}$ & $\begin{array}{l}\text { P- } \\
\text { Value }\end{array}$ & $\begin{array}{l}\text { Diagnostic } \\
\text { Tests }\end{array}$ \\
\hline Constant & 0.4708 & 0.0406 & 11.610 & 0.000 & $\begin{array}{l}\mathrm{R}^{2} \\
\text { adjusted }\end{array}$ \\
\hline Industrial Production & -0.0071 & 0.0017 & -4.223 & 0.000 & 0.2742 \\
\hline Total Borrowings & 0.0874 & 0.0276 & 3.170 & 0.001 & F-statistic \\
\hline 3-monthly interest rates & -0.1463 & 0.0350 & -4.177 & 0.000 & $\begin{array}{l}10.363 \\
{[0.000]}\end{array}$ \\
\hline Public Debt & 0.0009 & 0.0005 & 1.791 & 0.037 & \\
\hline Unemployment Rate & 0.0196 & 0.0182 & 1.076 & 0.141 & \\
\hline Oil Prices & 0.0027 & 0.0036 & 0.739 & 0.230 & \\
\hline Bank Prime Loan Rate & 0.1437 & 0.0280 & 5.135 & 0.000 & \\
\hline GDP Growth & -14.9645 & 1.7446 & -8.578 & 0.000 & \\
\hline
\end{tabular}


Table 10. Prediction results binary fuzzy regression with sigmoid membership function for in-sample period 1913-2005

\begin{tabular}{llll}
\hline Actual & \multicolumn{2}{l}{ Prediction } & \\
\hline & Crisis & No Crisis & Correctly percentage rate \\
Crisis & 36 & 8 & 81.81 \\
No Crisis & 54 & 250 & 82.23 \\
Overall percentage & & & 82.18 \\
\hline
\end{tabular}

Table 11. Prediction results of binary fuzzy regression with sigmoid membership function for out-of sample period 2006-2009

\begin{tabular}{llll}
\hline Actual & \multicolumn{3}{l}{ Prediction } \\
\hline & Crisis & No Crisis & Correctly percentage rate \\
Crisis & 9 & 0 & 100.00 \\
No Crisis & 1 & 6 & 85.71 \\
Overall percentage & & & 93.75 \\
\hline
\end{tabular}

\section{DISCUSSIONS}

The common result between the two methodologies is that the estimated coefficients present the same sign. On the other hand the differences are in the significance magnitude of the explanatory variables. More specifically with Logit and Probit models we found that the bank prime loan rate effects positively to a crisis occurrence more significant than the other variables and GDP growth has the strongest negative magnitude on probability of financial crisis occurrence, only in the case of Probit estimation. So the significant increase in the bank prime loan rate as also the low GDP growth might be two of the main reasons of the current crisis. Also the oil prices, the unemployment rate and the total borrowings, based on the Logit model are additional factors which might have led to the crisis occurrence.

Furthermore there are differences in the estimations between Probit-Logit and fuzzy models for two main reasons. First and most significant the Logit-Probit estimations were done with crisp numbers, while fuzzy regression estimation involves fuzzy number and fuzzy rules. Second the estimation regression models are different, while Logit-Probit models were estimated with maximum likelihood and fuzzy regressions have been estimated with the ordinary least squares method. Our main interest is not only to get significant and superior forecasts, but also reliable estimations. Both Probit and fuzzy models might provide reliable estimations and so can be used simultaneously for policy decisions. On the other hand we have shown that the forecasting performance of Logit-Probit models is low in the out-of sample period. For this reason we prefer to rely on fuzzy regressions which have an overall success of $93.75 \%$ 
and success in crisis periods predictions of $100.00 \%$ in the out-of sample period. This paper shows that fuzzy regression can be useful for prediction of four years as we apply here and specifically we forecast for sixteen periods ahead, because we have quarterly data for period 2006-2009. Finally, in Table 12 we present the forecast for the next four quarter in 2010 based on Logit model, while on Table 13 the same estimations are reported based on Probit and fuzzy models. With all models we estimate that the economic recession will be continued during 2010 and more specifically based on Logit model the economic recession will be continued in 2010 , while based on Probit and fuzzy models, we estimate that economic recession might take over in the second quarter of 2010 and the economic growth will start in the second half of 2010. But we should notice the following. First the unemployment rate will be remain stable around $10.00 \%$ and the bank prime loan rate around 3.25. Also the estimated values for GDP growth range between $2.30 \%$ and $2.50 \%$ and the oil prices around 80.00-90.00 dollars per barrel. So with Logit model we estimate that the economic recession will be continued in the whole period of 2010, because the significance of GDP growth is zero in Logit estimations, while on the contrary based on Probit and fuzzy models the significance of GDP growth is very high, which is the most logical explanation and for this reason we rely our predictions in the last two models. But on the other hand if GDP growth won't reach the estimated levels and specifically reach $1.50-1.80 \%$ as also the oil prices reach the levels of 100 dollars, then the economic recession will be continued in the second half of 2010 too and additionally a new oil crisis might be arise. Also the GDP growth in USA is based on exports activity, which is owed on the depreciation of US dollar against Euro and constitutes the US products much cheaper. But this trend is very possible to be continued during 2010 which might lead to the increase of gold and oil prices. Even if the financial crisis is over we haven't yet seen the complete results in the real economy, which are the wages, the unemployment rate and the consumption expenditure among others.

Table 12. Prediction results of Logit regression for 2010

\begin{tabular}{ll}
\hline Prediction & \\
\hline Crisis & No Crisis \\
4 & 0 \\
\hline
\end{tabular}

Table 13. Prediction results of Probit and Fuzzy regressions for 2010

\begin{tabular}{ll}
\hline Prediction & \\
\hline $1^{\text {st }}$ Quarter & Crisis \\
$2^{\text {nd }}$ Quarter & Crisis \\
$3^{\text {rd }}$ Quarter & No Crisis \\
$4^{\text {th }}$ Quarter & No Crisis \\
\hline
\end{tabular}




\section{CONCLUSIONS}

In this paper we examined and applied three different approaches in financial crisis prediction modeling. The first two were Logit and Probit regressions estimated with maximum likelihood and crisp dependent variable of values one and zero. We have shown that the correctly classification percentage and the forecasting performance of Logit regression is very poor in the out-of sample period, while it is high in the in-sample period, which period is of minor interest and importance. Probit regression exhibits higher forecasting performance than Logit in both in-sample and out-of sample periods. On the other hand we estimated a fuzzy regression with sigmoid membership function and we concluded that the forecasting performance of fuzzy regression is much more significant in the out-of sample period than traditional discrete choice Logit and Probit model. This indicates the superiority of fuzzy logic and artificial intelligence models suggesting that is a powerful tool for the economic policy makers. We estimate that the economic recession will be continued during 2010 as the unemployment rate has been increased at the highest level since the Great depression and if the GDP growth won't reach the estimated levels, as also if oil price will exceed the 90.00 dollars per barrel a new economic recession will be followed in 2010 with possible economic recovery in 2011. This paper suggests the use of fuzzy regressions and of more advanced methods of artificial intelligence for further study and research as also the adaptation of this approach by governments and the responsible personnel for the economic policies plans.

\section{REFERENCES}

AZNARTE, B.;CASTRO, L.J. (2007). "Smooth transition autoregressive models and fuzzy rule-based systems: Functional equivalence and consequences". Fuzzy Sets and Systems, No. 158, p. 2734-2745.

CHEN, W-S.; DU, Y-K. (2009). "Using neural networks and data mining techniques for the financial distress prediction model". Expert Systems with Applications: An International Journal, Vol. 26, No. 2, p. $4075-4086$.

COATS, P.K.; FANT, F.L. (1993). "Recognizing financial distress patterns using a neural network tool". Financial Management, No. 22, p. 142-155.

Demirguc-Kunt, A.; Detragiache, E. (1998). "The Determinants of Banking Crises in Developing and Developed Countries". IMF Staff Papers, Vol. 45, No. 1, p. 81-109.

EICHengreen, B.; Rose, A.K. (1998). "Staying Afloat When the Wind Shifts: External Factors and Emerging-Market Banking Crises". NBER Working Paper, No. 6370, Cambridge, Massachusetts.

FernandeZ, E.; Olmeda, I. (1995). "Bankruptcy prediction with artificial neural networks". Lecture Notes of Computer Science, No. 930, p. 1142-1146.

FRANKEL, J.; Rose, A.K. (1996). "Currency Crashes in emerging Markets: An Empirical Treatment". International Finance Discussion Papers, Board of Governors of the Federal Reserve System, No. 534.

GLICK, R. ; Rose A.K. (1998). "Contagion and trade: Why currency crises are regional?". NBER WORKING PAPER, No. 6806. 
Glick, R.; MoReno, R. (1999). "Money and Credit, Competitiveness and Currency Crises in Asia and Latin America". Working paper, Center for Pacific Basin Money and economic Studies, BP99-01, Federal Reserve Bank of San Francisco, March.

HAMILTON, J.D. (1989). "A new approach to economic analysis of nonstationary time series and the business cycle". Econometrica, No. 57, p. 357-384.

KAMINSKY, L.G.; REINHART, C.M. (1996). "The Twin Crises: The Causes of Banking and Balance of Payments Problems". Federal Reserve Board Discussion Paper, No. 544, Washington, D.C.

KAMINSKY, L.G.; LIZONDO, S.; REINHART, C.M. (1998). "Leading Indicators of Currency Crises". IMF Staff Papers, Vol. 45, No. 1, p. 1-48.

MARIANO, R.; ShabBiR, T.; Gultekin, N.B. (2001). "Financial Crisis in South East Asia". WhartonSMU Research Center of Singapore Management University.

NACHEV, A. ; StoYANOV, B. (2007). "A Default ARTMAP Neural Networks for Financial Diagnosis". Proceedings of the International Conference on Data Mining. Las Vegas, Nevada (USA), June 25-28.

Papadopoulos, B.K.; SiRPI, M.A. (1999). "Similarities in Fuzzy Regression Models". Journal of Optimization Theory and Applications, Vol. 2, No. 2, p. 373-383.

ZHANG, G.; Hu, Y.; PATUWO, E.B. (1999). "Artificial neural networks in bankruptcy prediction: General framework and cross-validation analysis". European Journal of Operation Research, No. 116, p. 16-32. 